\title{
Acute respiratory failure in asthma
}

\author{
Said H. Soubra, ${ }^{1}$ Kalapalatha K. Guntupalli ${ }^{2}$
}

\begin{abstract}
Although asthma is a condition that is managed in the outpatient setting in most patients, the poorly controlled and severe cases pose a major challenge to the health-care team. Recognition of the more common insidious and the less common rapid onset "acute asphyxic" asthma are important. The intensivist needs to be familiar with the factors that denote severity of the exacerbation. The management of respiratory failure in asthma, including pharmacologic and mechanical ventilation, are discussed in this article. Two important complications of the positive-pressure ventilation, the dynamic hyperinflation and barotrauma, may be lifethreatening. Interventions with helium-oxygen mixtures, anesthesia, and paralysis may be considered in certain situations.
\end{abstract}

Key Words: Asthma, Intensive care, Mechanical ventilation, Severe asthma

\section{Introduction}

Asthma is a chronic inflammatory disease of the airways. Patients with asthma are predisposed for developing exacerbations, leading to respiratory failure. Recognizing patients at risk, careful assessment, and rapid institution of appropriate treatment is of paramount importance for favorable outcome. In this paper, we will review the management of patients presenting with severe asthma and respiratory failure.

\section{Epidemiology}

Asthma affects 100-150 million people worldwide. It accounts for 180,000 deaths annually. In India, it is estimated that approximately 15-20 million people are affected. ${ }^{[1]}$ In 2002, the overall prevalence of lifetime asthma in the United States was $11.9 \%(N=24.7$ mil-

\section{From:}

1Section of Pulmonary and Critical Care Medicine, Baylor College of Medicine, Michael E. Debakey Veterans Affairs Medical Center, Houston, Texas 77030, USA

'Baylor College of Medicine, Pulmonary and Critical Care Medicine, MICU, Ben Taub General Hospital, Houston, Texas 77030, USA

\section{Correspondence:}

Said Soubra, Michael E. Debakey VAMC, Section of Pulmonary and Critical Care Medicine, 2002 Holcombe, MCL-111, Houston, Texas 77030, USA.

E-mail: saids@bcm.tmc.edu lion). ${ }^{[2]}$ Although in 1978-1989 there was a near-doubling in asthma mortality rates in the US, reaching 5000 deaths per year, ${ }^{[3]}$ a more recent study showed that in 1995-2002 age-adjusted asthma mortality has declined by $22.2-38.4 \%$. Age-adjusted asthma hospitalization has also significantly declined over the last decade. ${ }^{[4]}$ Nonetheless, asthma still poses significant burden on healthcare resources, accounting for 1.8 million emergencyroom visits, 500,000 hospitalizations, and 5000 deaths yearly in the US. ${ }^{[5]}$ Although the rate of intensive-careunit (ICU) admissions is declining, approximately $4-7 \%$ of patients admitted to the hospital with asthma may require ICU care. ${ }^{[6]}$ The total estimated cost of asthma in 1994 was $\$ 5.8$ billion, with hospitalization accounting for more than half of all expenditures. It was also estimated that $80 \%$ of resources were used by $20 \%$ of affected population (defined as "high-cost patients"). ${ }^{[7]}$

\section{Definitions}

The presentation of patients with severe asthma exacerbation has been given different terms, including status asthmaticus, near-fatal asthma, acute fatal asthma, and acute asphyxic asthma. Status asthmaticus refers to the attacks in which bronchial obstruction is severe 
from the outset or continues to worsen despite institution of conventional therapy, leading to respiratory failure and death. Near-fatal asthma was described in 1991 by Molfino as being a patient with an acute asthma attack of sudden onset, rapidly progressive, with extreme hypercapnea, and hypoxemia leading to a respiratory arrest. It was determined that the near-fatal nature of the attack was owing to the severe asphyxia rather than cardiac arrythmias. ${ }^{[8]}$ Sudden ashpyxic asthma was recognized by Wasserfallen as a group of patients presenting with rapid decompensation, with occurrence of endotracheal intubation in less than $3 \mathrm{~h}$ of onset of symptoms ${ }^{[9]}$ Robin, in 1989, described the course of four patients with acute fatal asthma, in which respiratory failure and death occurred within minutes of being symptom-free. ${ }^{[10]}$

\section{Presentation}

Two distinct presentations of acute, severe deterioration of asthma are described in Table 1. The first group of patients has a slow onset of the acute deterioration, with progression over hours to days to even weeks. This group comprises $80-90 \%$ of patients presenting to the Emergency Department (ED). Those patients have more airway inflammation; the inflammation is characterized by predominance of eosinophils, is more frequently triggered by upper respiratory airway infections, and is slow to respond to therapy. The other group of patients termed asphyxic or hyperacute asthma, present with sudden onset, rapid progression (3-6 $\mathrm{h}$ from the onset of symptoms), is triggered by allergens, exercise, and physiological stress, and usually responds rapidly to therapy. Those patients are thought to have a bronchospatic mechanism of deterioration and usually have a predominance of neutrophils in the airways rather than eosinophils. ${ }^{[6]}$

\section{Initial Evaluation and Assessment of Asthma Severity}

On presentation of the patient, a brief history and physical examination should be performed to assess immediate needs. Several factors have been identified to predict mortality from asthma. These include history of prior sudden severe exacerbations, prior endotracheal intubations, prior ICU admissions, increased use of shortacting $\beta_{2}$-agonists (SABAs), and current or recent withdrawal of systemic steroid use. A list of risk factors for asthma death is shown in Table 2. ${ }^{[11]}$ Patients with risk factors of asthma deaths should receive prompt and aggressive management. During the initial survey, several features in the history and physical examination may help the physician in assessing the severity of the asthmatic attack. These include the level of breathlessness, alteration in mental status, alterations in heart rate, respiratory rate, presence or absence of wheezing, use of accessory muscles, and presence of pulsus paradoxus. ${ }^{[11]} \mathrm{A}$ classification of the severity of asthma exacerbation is detailed in Table 3. Some of the features

Table 2: Risk factors associated with increased risk of death from asthma

Past history of sudden severe exacerbations Prior intubation for asthma

Prior admission for asthma to an ICU

Two or more hospitalizations for asthma in the last year

Three or more emergency-care visits for asthma in the last year Hospitalization or an emergency-care visit for asthma within the last month

Use of two or more canisters per month of inhaled SABA

Current use or recent withdrawal of systemic corticosteroids

Difficulty perceiving airflow obstruction or its severity

Comorbidity (cardiovascular diseases or chronic obstructive pulmonary disease)

Serious psychiatric disease or psychosocial problems

Illicit drug use

Sensitivity to alternaria

Adapted from Ref. 11

\section{Table 1: Two characteristic presentations of acute severe asthma}

\begin{tabular}{ll}
\hline Type 1: Slow progression & Type 2: Sudden progression \\
Slow-onset acute asthma & Sudden-onset, asphyxic, brittle, hyperacute asthma \\
Progressive deterioration: more than $6 \mathrm{~h}$ (usually days or weeks) & Rapid deterioration \\
$80-90 \%$ Patients who present to ED & $10-20 \%$ Patients who present to ED \\
Female predominance & Male predominance \\
More likely to be triggered by URI & More likely to be triggered by respiratory allergens, exercise, and \\
& psychological stress \\
Less severe obstruction at presentation & More severe obstruction at presentation \\
Slow response to treatment and higher hospital admissions & Rapid response to treatment and lower hospital admissions \\
Airflow inflammation mechanism & Bronchospastic mechanism \\
Predominance of eosinophils & Predominance of neutrophils \\
\hline
\end{tabular}

Adapted from Ref. 6. URI, upper respiratory infection. 
Table 3: Classification of severity of asthma exacerbation

\begin{tabular}{|c|c|c|c|c|}
\hline Symptoms & Mild & Moderate & Severe & Respiratory arrest imminent \\
\hline Breathlessness & While walking & While talking & While at rest & \\
\hline Can lie down & Prefers sitting & Sits upright & & \\
\hline Talks in & Sentences & Phrases & Words & \\
\hline Alertness & May be agitated & Usually agitated & Usually agitated & Drowsy or confused \\
\hline \multicolumn{5}{|l|}{ Signs } \\
\hline Respiratory rate & Increased & Increased & Often (>30/min) & \\
\hline $\begin{array}{l}\text { Use of accessory muscles; } \\
\text { thoracoabdominal }\end{array}$ & Usually not & Commonly & Usually & Paradoxical \\
\hline suprasternal retractions & & & & movement \\
\hline Wheeze & $\begin{array}{l}\text { Moderate, often } \\
\text { only end-expiratory }\end{array}$ & $\begin{array}{l}\text { Loud, throughout } \\
\text { exhalation }\end{array}$ & $\begin{array}{l}\text { Usually loud, } \\
\text { throughout inhalation } \\
\text { and exhalation }\end{array}$ & Absence of wheeze \\
\hline Pulse/min & $<100$ & $100-120$ & $>120$ & Bradycardia \\
\hline $\begin{array}{l}\text { Pulsus paradoxus } \\
(\mathrm{mm} \mathrm{Hg})\end{array}$ & $<10$ (absent) & $\begin{array}{l}10-25 \\
\text { (may be present) }\end{array}$ & $>25$ (often present) & $\begin{array}{l}\text { Absence suggests } \\
\text { respiratory muscle fatigue }\end{array}$ \\
\hline \multicolumn{5}{|l|}{ Functional assessment } \\
\hline $\begin{array}{l}\text { PEF } \\
\text { (\% predicted or } \\
\text { personal best) }\end{array}$ & $>80$ & $\begin{array}{l}\text { Approximately } \\
50-80 \text { or response } \\
\text { response last }<2 \mathrm{~h}\end{array}$ & $<50$ & \\
\hline $\mathrm{PaO}_{2}(\mathrm{~mm} \mathrm{Hg})$ & Normal & $>60$ & <60; possible cyanosis & \\
\hline $\mathrm{PaCO}_{2}(\mathrm{~mm} \mathrm{Hg})$ & $<42$ & $<42$ & $\begin{array}{l}\geq 42 \text {; possible respiratory } \\
\text { failure }\end{array}$ & \\
\hline $\mathrm{SaO}_{2}$ (\%; on air) & $>95$ & $91-95$ & $<91$ & \\
\hline
\end{tabular}

Adapted from Ref. 11. The presence of several parameters, but not necessarily all, indicates the general classification of the exacerbation. Many of these parameters have not been systematically studied, so they serve only as general guides.

are suggestive of imminent need for assisted ventilation; these include cyanosis, inability to speak more than few words, severe agitation or confusion, absence of wheezing, or weak respiratory efforts, suggestive of muscle fatigue. Presence of these features should prompt the institution of maximal therapy, including assisted ventilation. It is important to note that the evaluation of patients with asthmatic exacerbation should be dynamic, with repeated examination after each therapeutic intervention. Objective measurement of indices of ventilation and oxygenation is important both to establish a baseline and to monitor response to treatment. Peak expiratory flow rate (PEFR) measurement should be used in the emergency room to quantify airflow obstruction and to evaluate response to treatment. Oxygen saturation measurement or blood-gas analysis may be of value to show evidence of hypoxemia and/or respiratory acidosis, indicating the presence of a severe asthmatic attack.

\section{Initial Management of Patients not Requir- ing Mechanical Ventilation \\ Oxygen Supplementation}

Correction of significant hypoxemia with supplemental oxygen is extremely important and is the first step in the management patients presenting with asthmatic exacerbation. Supplemental oxygen therapy should be started by prehospital providers. ${ }^{[11]}$ It is recommended to provide $\mathrm{O}_{2}$ to maintain $\mathrm{O}_{2}$ saturation at $\mathrm{SaO}_{2}>90 \%(>95 \%$ in pregnant patients and in patients with coexistent heart disease). Oxygen saturation should be monitored until response to bronchodilator therapy has occurred. ${ }^{[11]}$

\section{Inhaled Bronchodilator Therapy \\ $S A B A s$}

Inhaled SABAs remain the mainstay of therapy in patients presenting with an acute exacerbation of asthma. A variety of $\beta_{2}$-selective SABAs are being used, including albuterol (salbutamol), bitolterol, and pirbuterol. $\beta_{2}$. Selective agents are preferred owing to the reduced risk of cardiotoxicity at high doses when compared with nonselective agents. ${ }^{[11]}$ Inhaled SABA can be administered in frequent repetitive administrations or continuous nebulization (10-15 mg/h albuterol). A Cochrane review was performed and published in 2003, comparing intermittent vs continuous $\beta$-agonists; 157 trials were included with a total of 461 patients studied. ${ }^{[12]}$ Continuous $\beta_{2}{ }^{-}$ agonist therapy was shown to reduce the overall admission to the hospital, with patients with severe airway obstruction benefiting the most. Improvement in pulmonary function including FEV1 (forced expiratory volume in 1) and PEFR was greater in the continuous group. There were no significant differences in pulse rate, blood pressure, incidence of tremor, and potassium concentration. 
Inhaled SABA can be administered using either meter-dose inhaler with spacer device or nebulizer. Several studies have shown equivalence in the degree of bronchodilation achieved with the two methods. ${ }^{[13-15]}$ The equivalent dose needed to achieve similar bronchodilation to a $2.5-\mathrm{mg}$ nebulized albuterol is approximately 6-12 puffs. Some patient groups, including children, elderly, agitated patients, or patients with severe asthma, may not be able to coordinate inhalation of the medication from an MDI (metered dose inhaler) and may require nebulization. ${ }^{[12]}$

Racemic albuterol comprises two enantiomers, $(R)$ albuterol and $(S)$-albuterol. The two enantiomers have different pharmacologic properties. Whereas $(R)$ albuterol has bronchodilator properties, $(S)$-albuterol in animal models has been shown to cause increased airway responsiveness. ${ }^{[16]}$ Recently, an $(R)$-stereoisomer of albuterol (levalbuterol) was approved for clinical use. Two prospective, randomized, controlled trials examined the clinical efficacy of levalbuterol in the treatment of acute asthma in the pediatric population as compared with racemic albuterol. ${ }^{[17,18]}$ Outcome measures examined included change in spirometric measurements, changes in physiologic parameters, frequency of hospitalization, and length of emergency room care. Both studies showed equivalence of both drugs. A single study of the use of levalbuterol in acute asthma in adults was identified. ${ }^{[19]}$ Nowak et al. in this prospective, open-label, nonrandomized pilot study evaluated the efficacy of levalbuterol in acute asthma in 91 patients. Patients receiving levalbuterol had greater spirometric response when compared with albuterol at different doses. Further studies are needed to elucidate a possible role for levalbuterol in the treatment of acute asthma especially owing to the greater cost of levalbuterol.

\section{Anticholinergics}

Although $\beta_{2}$-agonists are the first-line bronchodilating agents in the treatment of an acute asthmatic exacerbation, ipratropium bromide should be considered as an additive treatment. A meta-analysis examined the role of ipratropium bromide in the treatment of acute asthma in both adults and children. ${ }^{[20]}$ There was a modest statistical improvement in airflow obstruction when ipratropium was added to $\beta_{2}$-agonists. Although clinical outcomes were improved in children, this was not established in adults. There was no attributable increase in side effects when ipratropium bromide was used in conjunction with albuterol. Because ipratropium provides improved bronchodilation without risk of adverse effects, it is recommended to be used in addition to albuterol in the treatment of acute asthma exacerbation. ${ }^{[11]}$

\section{Corticosteroids}

Systemic corticosteroids are recommended for most patients with acute exacerbation of asthma. ${ }^{[11]}$ Systemic corticosteroids have been shown to cause significantly greater and more rapid resolution of airflow obstruction, ${ }^{[21]}$ reduce the rate of admissions, as well as prevent relapse in the outpatient treatment of asthma. ${ }^{[22]}$ The optimal dose of corticosteroids varies in different studies. Manser et al., in a recent Cochrane review, examined nine trials that included a total of 344 patients. They were not able to show any difference among the different doses of corticosteroids in acute asthma requiring hospital admission. Lower doses of corticosteroids, such as less than or equal to $80 \mathrm{mg}$ daily of methylprednisolone or less than or equal to $400 \mathrm{mg}$ daily of hydrocortisone, appeared to be adequate for the initial treatment of an acute asthma exacerbation. ${ }^{[23]}$ Oral administration of corticosteroids is as effective as and less invasive than intravenous administration, and therefore, is the preferred route of therapy. ${ }^{[11]}$

Inhaled corticosteroids (ICS) have also been studied in the treatment of acute exacerbation of asthma. In seven trials that included a total of 376 patients; ICS was shown to reduce the rate of admission to the hospital. This was more evident in the subgroup of patients not receiving systemic steroids. ICS significantly improved peak expiratory flow rates and FEV1. The treatment was well tolerated, with few reported adverse side effects. A comparison of ICS to systemic steroids alone could not be made with the available data. ${ }^{[24]}$

\section{Methylxanthines}

Methylxanthines are generally not recommended as part of the management of patients with acute exacerbation of asthma in the ED. In addition, the NIH NAEPP expert panel report 2 does not recommend the use of theophylline in children hospitalized with asthma or reports that the addition of intravenous theophylline in hospitalized adults remains controversial. ${ }^{[11]}$ However, recent literature examined the use of theophylline mainly in hospitalized children not responding to maximal treat- 
ment (oxygen, inhaled bronchodilators, and glucocorticoids). A Cochrane review examined seven trials with a total of 380 participants. ${ }^{[25]}$ All studies recruited children with acute severe asthma requiring hospital admission. Most of the patients were unresponsive to conventional therapy. The review showed that the addition of aminophylline significantly improved FEV1 and PEF percent-predicted; however, there was no statistical difference in the length of hospital stay, symptoms, frequency of nebulizations, or mechanical ventilator rates. The most common side effect was vomiting. There was no significant difference in other side effects, which include hypokalemia, headaches, tremors, seizures, arrythmias, and death. ${ }^{[25]}$ Data to recommend the use of aminophylline in adults is lacking. The potential use of intravenous aminophylline is in patients with status asthmaticus, resulting in respiratory failure, and is resistant to maximal conventional therapy. However, it is important to note that the administration of aminophylline should be done by a clinician who is competent in dosing, monitoring serum levels, and assessing factors that modify clearance. Further research is needed to examine the role of aminophylline use in this extremely critical group of patients.

\section{Magnesium Sulfate}

Magnesium sulfate has been used as adjunct to standard therapy in patients with an acute exacerbation of asthma. Magnesium is a predominantly intracellular cation. Magnesium supplementation has been shown to cause bronchodilation. ${ }^{[26,27]}$ It is thought to produce this effect by inhibition of smooth muscle contraction through competitive antagonism with calcium; it may also be involved in acetylcholine and histamine release, in addition to possible role as an anti-inflammatory agent. Magnesium has been studied through either intravenous or inhalational administration. Rowe et al., in a review of the trials of intravenous magnesium sulfate in the treatment of acute asthma in the ED, examined seven trials with a total of 668 patients treated. ${ }^{[28]}$ The dose of magnesium used in these trials was approximately 1-2 $\mathrm{g}$. Magnesium was added to conventional therapy that included $\beta_{2}$-agonists and steroids. Although in the overall group, magnesium sulfate did not result in a reduction of hospital admissions, it was shown to be effective in reducing admission in the severe subgroup. Similarly, peak flow rate and FEV1 improved only in the patients with severe asthma exacerbation. In this study there were no significant changes in vital signs or side effects. However, magnesium may cause flushing and vasodilation, leading to transient hypotension. Therefore, although intravenous magnesium sulfate is not recommended for routine use in patients with acute asthma, it may have a role in the treatment of patient with severe asthma exacerbation needing hospitalization and ICU care.

Inhaled magnesium sulfate has been studied in the treatment of acute asthma with variable results. A recent systematic review of six trials (296 patients) was performed. ${ }^{[29]}$ Four studies compared the addition of inhaled $\mathrm{MgSO}_{4}$ to nebulized albuterol and two studies compared inhaled $\mathrm{MgSO}_{4}$ alone to nebulized albuterol. The doses of inhaled magnesium were highly variable. The pooling of data showed a significant improvement in lung function, with no difference in the rate of hospitalization. This effect was more pronounced in the most severe cases.

\section{Heliox}

Helium is a colorless, odorless, non-inflammable gas discovered in 1968. Its medical use as a carrier gas for oxygen instead of nitrogen was first described by Barach in 1930. It was used mainly for treatment of respiratory failure owing to upper airway obstruction. Barach also used helium-oxygen mixture in the treatment of acute exacerbation of asthma; however, it fell out of favor after the advent of bronchodilators. ${ }^{[30]}$ Helium has a very low density $(0.43 \mathrm{~g} / \mathrm{l})$, which is one-seventh of the density of air. Owing to its low density, helium improves gas flow through high-resistance airways by increasing laminar flow. ${ }^{[31]}$ Helium-oxygen mixtures can vary in the concentration of oxygen, depending on the level of hypoxia $(80 / 20,70 / 30$, or $60 / 40)$. Heliox has been studied in the treatment of nonintubated acute asthma patients in several studies. Rodrigo et al. systematically examined the literature in a Cochrane review. Six randomized controlled trials were included, with a total of 369 patients. ${ }^{[32]}$ Patients treated with Heliox did not show any improvement in pulmonary function. Heliox did not reduce the rate of hospital admission. It has also been studied in patients receiving mechanical ventilation. It was shown, in small studies, to improve oxygenation and respiratory acidosis, and decrease peak airway pressures. ${ }^{[33-35]}$ It is, however, important to note that helium can interfere in the measurement of pressure and volume during mechanical ventilation. Heliox has also been 
studied as a vehicle to carry bronchodilators distally into the lung. Bag et al. ${ }^{[36]}$ and Kress et al. ${ }^{[37]}$ have examined the role of Heliox as a driving gas for delivering the bronchodilator-both have shown improvements in FEV1. Kress et al. ${ }^{[37]}$ randomized 45 patients to receive albuterol nebulized with either oxygen or heliox $80 / 20$ as the driving gas. The treatment group (Heliox group) had significantly larger improvement in FEV1 after each inhalation.

\section{Noninvasive Ventilation}

Noninvasive ventilation has been shown to be effective in the treatment of hypercapneic respiratory failure secondary to acute exacerbation of chronic obstructive pulmonary disease. ${ }^{[38]}$ Respiratory failure in acute exacerbation of asthma is thought to be similar to chronic obstructive pulmonary disease. A review of the literature revealed several studies examining the role of noninvasive ventilation in patients with acute exacerbation of asthma. ${ }^{[39]}$ Only one study was prospective, randomized, and controlled. ${ }^{[40]}$ In this trial, Soroksky et al. randomized 30 patients with a severe asthma attack to bilevel positive pressure ventilation plus conventional therapy $(N=15)$ and conventional therapy alone $(N=15)$. Patient treated with noninvasive ventilation had a significant improvement in FEV1 and a reduced rate of hospitalization. Although the use of noninvasive ventilation in patients with acute exacerbation of asthma looks promising, further large, randomized trials are needed. Noninvasive ventilation has its limitations. It should only be used on awake and cooperative patients. Patients requiring airway protection and frequent suctioning as well as patients with facial trauma should not be treated with this modality.

\section{Invasive Mechanical Ventilation Indications}

The need for mechanical ventilation in patients presenting with status asthmaticus varies considerably in the medical literature ranging from 2 to $70 \%$ with a mean of $31.8 \% .{ }^{[4]]}$ The indications for intubation and mechanical ventilation usually are progressive hypercapnia, obtundation, and impending cardiopulmonary collapse. Hypercapnia alone does not protend need for mechanical ventilation. In a study by Mountain et al., ${ }^{[42]}$ only $8 \%$ of patients presenting with hypercapnia required mechanical ventilation.

\section{Endotracheal Intubation}

Once intubation and mechanical ventilation have been deemed necessary, it is important not to delay the intubation procedure and preferably perform the procedure electively under controlled conditions. ${ }^{[11,43]}$ Rapid sequence intubation should be performed by the most experienced operator to prevent bronchospasm. Bronchospasm is best prevented by pretreatment with inhaled albuterol. Intravenous lidocaine has not been shown to attenuate intubation-induced bronchospasm. ${ }^{[44]}$ The oral route is the preferred route for intubation in patients with status asthmaticus, as it allows the use of larger size endotracheal tubes, thereby decreasing airway resistance and allowing better suctioning of secretions and mucous plugs. ${ }^{[43]}$ Nasal intubation, however, can be performed on conscious patients with minimal need for sedatives.

\section{Sedation and Paralysis}

Deep sedation and occasionally paralysis are required in patients with severe asthma on mechanical ventilation. Deep sedation can be achieved with a variety of agents, including benzodiazipines, opiates, and propofol. Although morphine is inexpensive and provides adequate analgesia, it has been associated with worsening bronchospasm owing to histamine release from mast cells. Additionally, morphine causes significant decrease in gut motility, causes chest wall rigidity, and lacks the amnestic effect provided by the benzodiazepines. ${ }^{[43,45]}$

Ketamine can also be used for sedation of patients with status asthmaticus. It has been shown to have an added effect of bronchodilation. ${ }^{[46]}$ However, dysphoria, hallucination, and increased pulmonary secretions limit its use. ${ }^{[47]}$ Propofol is an excellent agent for sedation in patients with respiratory failure secondary to asthma. Propofol provides the advantage of being short-acting, with a rapid onset of action and ease of titration. It has also been shown to reduce respiratory resistance. ${ }^{[48]}$ Disadvantages of Propofol include hypertriglyceridemia, decreasing the seizure threshold, and causing hypotension if the patient has inadequate intravascular volume.

It may be occasionally necessary to supplement sedation with neuromuscular blockade.

Neuromuscular blockers include depolarizing agents such as succinylcholine and nondepolarizing agents such 
as pancuronium, vecuronium, atracurium, and cisatracurium. Succinylcholine can be used for during induction of anesthesia to facilitate intubation and has been associated with prolonged paralysis in patients with pseudocholinesterase deficiency. Non-depolarizing agents on the other hand have been used for prolonged periods of time. Pancuronium and vecuronium are eliminated by the liver and kidney and therefore caution is needed in case of decrease in liver or kidney function. ${ }^{[49]}$ Neuromuscular blockers have been associated with prolonged muscle weakness requiring prolonged mechanical ventilation. Although this effect can be seen solely with the use of neuromuscular blockers, most patients with status asthmaticus receive high-dose steroids, causing further muscle weakness. ${ }^{[50]}$ In a retrospective cohort study, Leatherman et al. reviewed 107 patients with severe asthma needing mechanical ventilation. The incidence of muscle weakness was highest in the group of patients that received the combination of neuromuscular blockers and steroids. There was no evidence of weakness in the group of patients that received steroids only. ${ }^{[51]}$ Neuromuscular blockers that contain an aminosteroid nucleus are more likely to be associated with weakness. To reduce the risk of this devastating side effect, guidelines were suggested by Guntupalli et al. ${ }^{[45]}$ In patients requiring paralytics, an attempt at using the lowest possible dose should be made by using neuromuscular stimulators; CPK (creatinine phosphokinase) levels should be monitored, and drug holidays and early withdrawal of the medication should be attempted.

\section{Ventilatory Strategy}

Expiratory airflow limitation and dynamic hyperinflation are the predominant pathophysiologic features in patients with status asthmaticus. Mechanical ventilation strategies in these patients should be aimed at prolonging expiratory time, thereby reducing end-expiratory lung volume. Dynamic hyperinflation referred to as "autoPEEP" occurs owing to several factors including increased ventilatory requirements and prolonged expiratory time constant secondary to airflow obstruction owingg to inflammation and mucus plugging as well as premature closure of airways during exhalation. This results in significant increase in work of breathing and increased inspiratory threshold for initiation of a breath. ${ }^{[52]}$ Dynamic hyperinflation can be suspected by findings of increased peak airway pressure as well as persistence of expiratory flow at the time of initiation of the second breath. It should also be suspected when the patient is unable to trigger the ventilator despite respiratory efforts, hemodynamic instability, or pulseless electrical activity (PEA). ${ }^{[45]}$ Figure 1 shows findings on respiratory waveforms, which suggest the presence of dynamic hyperinflation. As noted, peak airway pressure is elevated. Plateau pressure which is measured at the end of inspiration by applying an inspiratory hold is also elevated. When an occlusion maneuver is performed at end of expiration, "auto-peep" can be detected by the presence

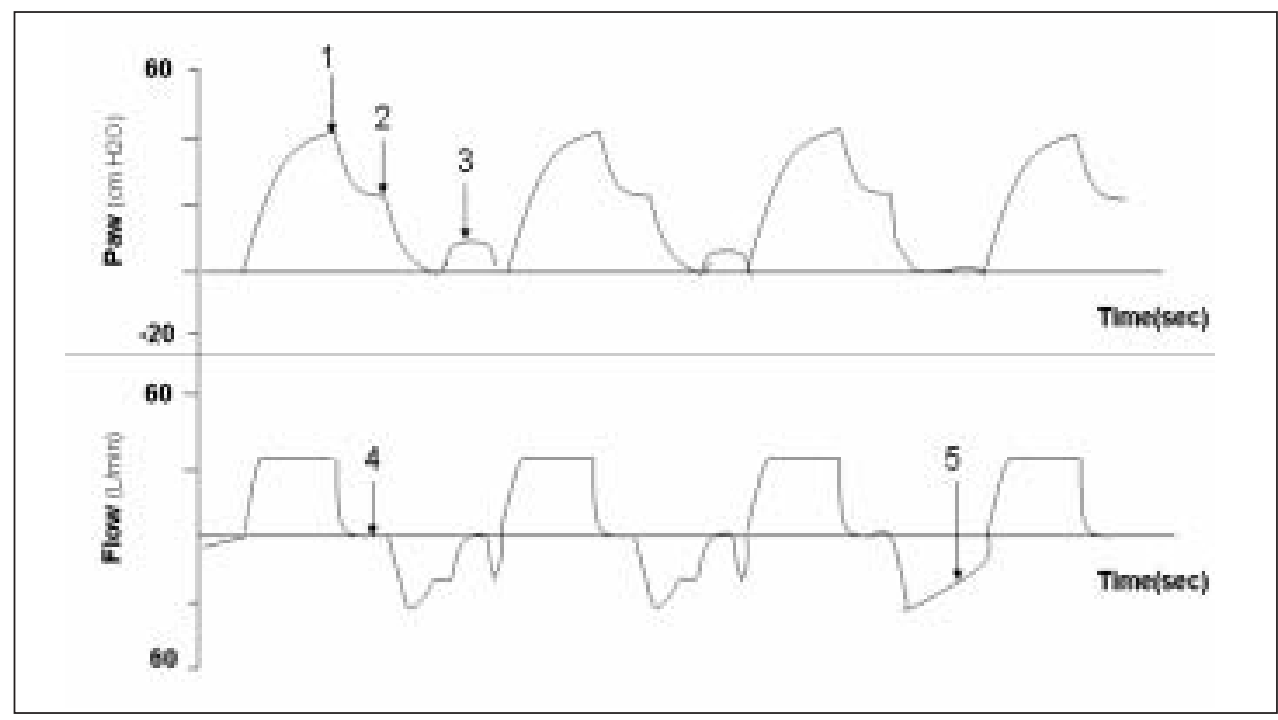

Figure 1: Airway pressure $\left(\mathrm{cm} \mathrm{H}_{2} \mathrm{O}\right)$ and respiratory flow $(\mathrm{l} / \mathrm{min})$ vs time $(\mathrm{s})$ in a patient with severe asthma and dynamic hyperinflation. (1) Peak airway pressure, (2) plateau pressure, (3) auto-PEEP detected after an expiratory hold maneuver, (4) inspiratory hold maneuver to measure plateau pressure, and (5) expiratory flow not returning to baseline prior to initiation of inspiration 
of airway pressure. Note the persistence of flow at the end of expiration, suggesting a prolonged expiratory time constant. Exact measurement of the amount of autoPEEP (Peek End Expiratory Pressure) is difficult to perform owing to the persistence-obstructed hyperinflated alveoli that are not communicating with the airways.

Mechanical ventilation can be performed by either volume- or pressure-controlled ventilation. Traditionally, volume-controlled ventilation with tidal volumes of 8-10 $\mathrm{ml} / \mathrm{kg}$, inspiratory flow rate of 80-100 l/min, and a square waveform have been recommended. ${ }^{[45]}$ If dynamic hyperinflation is detected, then several maneuvers can be performed to reduce its occurrence. Reducing tidal volume, increasing peak flow rate, and reducing respiratory rate can all increase expiratory time and allow better emptying of the lung. Tuxen et al., ${ }^{[53]}$ however, were able to show that the effect of tidal volume changes on dynamic hyperinflation is of greater magnitude than changes in inspiratory flow rate. Similarly, reduction in respiratory rate can reduce dynamic hyperinflation; however, the magnitude of its effect is modest. ${ }^{[54]}$ PEEP can be used in selected patients with asthma. Low levels of PEEP have been shown to improve expiratory flow resistance as well as improving ventilator triggering and reducing work of breathing. ${ }^{[55]}$ Mechanical ventilation strategies to reduce dynamic hyperinflation often result in hypoventilation and respiratory acidosis. Significant hypercapnea is well tolerated, ${ }^{[56]}$ if necessary correction of the metabolic acidosis by adding a buffer can be achieved.

\section{Complications of Mechanical Ventilation}

The two most common complications of mechanical ventilation in patients with respiratory failure secondary to severe asthma are hypotension and barotrauma. $\mathrm{Hy}$ potension can develop owing to dynamic hyperinflation, positive pressure ventilation, pneumothorax, or sedation. PEA, previously known as EMD (Electro-mechanical dissociation), can occur in patients who are aggressively ventilated. ${ }^{[57]}$ If hypotension occurs secondary to dynamic hyperinflation, an expiratory pause or even disconnecting the patient from the ventilator and allowing the lungs to empty, can result in improvement in blood pressure. Barotrauma, on the other hand, should be suspected if the patient develops sudden hypotension, hypoxia, or subcutaneous emphysema. Barotrauma can occur in up to $27 \%$ of patients and it correlates well with end-expira- tory lung volumes. ${ }^{[58]}$ It is also important to note that ventilator-associated pneumonia can develop in this patient population and it carries a high morbidity and mortality.

\section{Conclusion}

Severe asthma management is complex and challenging. Careful assessment of these patients is needed to provide prompt and adequate treatment to reduce morbidity and mortality in this young population. Although much has been done in this field, research is still needed to better understand the pathophysiology of this disease and to provide new and better treatment modalities.

\section{References}

1. Bronchial Asthma, World Health Organization Fact Sheet Number 206, www.who.int/mediacentre/factsheets/fs206/en, January 2000.

2. CDC. Asthma Prevalence and Control Characteristics by Race/ Ethnicity-United States, 2002. MMWR 2004;53:145-8.

3. Arrighi HM. US asthma mortality: 1941 to 1989. Ann Allergy Asthma Immunol 1995;74:321-6.

4. Getahun D, Desmissie K, Rhoads GG. Recent trends in asthma hospitalization and mortality in the United States. J Asthma 2005;42:373-8.

5. Siwick JP, Nowak RM, Zoratti EM. The evaluation and management of acute, severe asthma. Med Clin N Am 2002;86:104971.

6. Rodrigo GJ, Rodrigo C, Hall JB. Acute asthma in adults: a review. Chest 2004;125:1081-102.

7. Smith DH, Malone DC, Lawson KA, Okamoto LJ, Battista C Saunders WB. A national estimate of economic costs of asthma. Am J Respir Crit Care Med 1997;156:787-93.

8. Molfino NA, Nannini LJ, Martelli AN, Slutsky AS. Respiratory arrest in near-fatal asthma. N Engl J Med 1991;324:285-8.

9. Wasserfallen JB, Schaller MD, Feihl F, Perret CH. Sudden asphyxic asthma: a distinct entity? Am Rev Respir Dis 1990;142:108-11.

10. Robin ED, Lewiston N. Unexpected, unexplained sudden death in young asthmatic subjects. Chest 1989;96:790-3.

11. National Heart, Lung, and Blood Institute. National Asthma Education and Prevention Program Expert Panel Report 2:Guidelines for the diagnosis and management of asthma. Publication No. 97-4051. Bethesda: National Institute of Health;1997.

12. Camargo, Jr, $\mathrm{CA}$, Spooner $\mathrm{CH}$, Rowe $\mathrm{BH}$. Continuous versus intermittent beta-agonists for acute asthma. The Cochrane Database of Systematic Reviews 2003, Issue 4. Article No.:CD001115. DOI:10.1002/14651858.CD001115.

13. Kerem E, Levison H, Schuh S, O'Borodovich H, Reisman J, 
Bentur L, et al. Efficacy of albuterol administered by nebulizer versus spacer device in children with acute asthma. J Pediatr 1993;123:313-7.

14. Colacone A, Afilalo M, Wolkove N, Kreisman H. A comparison of albuterol administered by metered dose inhaler (and holding chamber) or wet nebulizer in acute asthma. Chest 1993;104:83541.

15. Idris AH, McDermott MF, Raucci JC, Morrabel A, McGorray S, Hendeles L. Chest 1993;103:665-72.

16. Hoshiko K, Morley J. Exacerbation of airway hyperactivity by ( \pm ) salbutamol in sensitized guinea pigs. Jpn J Pharmacol 1993;63:159-63.

17. Hardasmalani MD, Debari V, Bithoney WG, Gold N. Levalbuterol versus racemic albuterol in the treatment of acute exacerbation of asthma in children. Pediatr Emerg Care 2005;21:415-9.

18. Qureshi F, Zaritsky A, Welch C, Meadows T, Burke BL. Clinical efficacy of racemic albuterol versus levalbuterol for the treatment of acute pediatric asthma. Ann Emerg Med. 2005;46:2936.

19. Nowak RM, Emerman CL, Schaefer K, DiSantostefano RL, Vaickus L, Roach JM. Levalbuterol compared with racemic albuterol in the treatment of acute asthma:results of a pilot study. Am J Emerg Med 2004;22:29-36.

20. Aaron SD. The use of ipratropium bromide for the management of acute asthma exacerbation in adults and children:a systemic review. J Asthma 2001;38:521-30.

21. Fanta $\mathrm{CH}$, Rossing $\mathrm{TH}, \mathrm{McFadden} \mathrm{FR}$, Jr. Glucocorticoids in acute asthma. A critical controlled trial. Am J Med 1983;74:84551.

22. Rowe BH, Keller JL, Oxman AD. Effectiveness of steroid therapy in acute exacerbations of asthma:a meta-analysis. Am J Emerg Med 1992;10:301-10.

23. Manser R, Reid D, Abramson M. Corticosteroids for acute severe asthma in hospitalized patients. The Cochrane Database of Systematic Reviews. 2001, Issue 1, Article No. CD001740. DOI:10.1002/14651858. CD001740.

24. Edmonds ML, Camargo, Jr, CA, Pollack, Jr, CV, Rowe BH. Early use of inhaled corticosteroids in the emergency treatment of acute asthma. The Cochrane Database of Systematic Reviews 2003, Issue 3. Article No CD002308. DOI:10.1002/14651858. CD002308.

25. Mitra A, Bassler D, Goodman K, Lasserson TJ, Ducharme FM. Intravenous aminophylline for acute severe asthma in children over two years receiving inhaled bronchodilators. The Cochrane Database of Systematic Reviews 2005, Issue 2. Article No.:CD001276.pub2. DOI:10.1002/14651858.CD001276.pub2

26. Okayama H, Aikawa T, Okayama M. Bronchodilating effect of intravenous magnesium sulfate in bronchial asthma. JAMA
1987;257:1076-8.

27. Rolla G, Bucca C, Caria E. Acute effect of intravenous magnesium sulfate on airway obstruction in asthmatic patients. Ann Aller 1988;61:388-91.

28. Rowe BH, Bretzlaff JA, Bourdon C, Bota GW, Camargo CA, Jr. Intravenous magnesium sulfate treatment of acute asthma in the emergency department: a systematic review of the literature. Ann Emerg Med 2000;36:181-90.

29. Blitz M, Blitz S, Beasely R, Diner BM, Hughes R, Knopp JA, et al. Inhaled magnesium sulfate in the treatment of acute asthma. The Cochrane Database of Systematic Reviews 2005, Issue 3. Article No. CD003898.pub3. DOI:10.1002/14651858. CD003898.pub3.

30. Reuben AD, Harris AR. Heliox for asthma in the emergency department: A review of the literature. Emerg Med J;21:131-5.

31. Gupta VK, Cheifetz IM. Heliox administration in the pediatric intensive care unit: An evidence-based review. Pediatr Crit Care Med 2005;6:204-11.

32. Rodrigo G, Pollack C, Rodrigo C, Rowe BH. Heliox for non-intubated acute asthma patients. The Cochrane Database of Systematic Reviews 2003, Issue 2. Article No. CD002884. DOI:10.1002/14651858. CD002884

33. Schaeffer EM, Pohlman A, Morgan S, Hall JB. Oxygenation in status asthmaticus improves during ventilation with helium-oxygen. Crit Care Med 1999;27:2666-70.

34. Gluck EH, Onorato DJ, Castriotta R. Helium-oxygen mixtures in intubated patients with status asthmaticus and respiratory acidosis. Chest 1990;98:693-8.

35. Abd-Allah SA, Rogers MS, Terry M. Helium-oxygen therapy for pediatric acute severe asthma requiring mechanical ventilation. Perditr Crit Care Med 2003;4:353-7.

36. Bag R, Bandi V, Fromm R, Guntupalli K, Helium oxygen mixtures in asthma. J Asthma 2002;39:659-65.

37. Kress JP, Noth I, Gehlbach BK, Barman N, Pohlman AS, Morgan S, et al. Am J Respir Crit Care Med 2002;165:1317-21.

38. Ram FSF, Picot J, Lightowler J, Wedzicha JA. Non-invasive positive pressure ventilation for treatment of respiratory failure due to exacerbations of chronic obstructive pulmonary disease. The Cochrane Database of Systematic Reviews 2004, Issue 3. Article No. CD004104.pub3. DOI:10.1002/14651858. CD004104.pub3

39. Ram FS, Wellington SR, Rowe B, Wedzicha JA. Non-invasive positive pressure ventilation for treatment of respiratory failure due to severe acute exacerbation of asthma. The Cochrane Database of Systematic Reviews 2005, Issue 3. Article No. CD004360.pub3. DOI:10.1002/14651858. CD004360. pub3.

40. Soroksky A, Stav D, Shpirer I. A pilot prospective, randomized, placebo-controlled trial of bilevel positive airway pressure in 
acute asthmatic attack. Chest 2003;123:1018-25.

41. McFadden ER. Acute severe asthma. Am J Respir Crit Care Med 2003;168:740-59.

42. Mountain RD, Sahn SA. Clinical features and outcome of patients with acute asthma presenting with hypercapnia. Am Rev Respir Dis 1988;138:535-9.

43. Jain S, Hanania NA, Guntupalli KK. Ventilation of patients with asthma and obstructive lung disease. Crit Care Clin 1998;14:685705.

44. Maslow AD, Regan MM, Israel E, Darvish A, Mehrez M, Boughton $\mathrm{R}$, et al. Inhaled albuterol, but not intravenous lidocaine protects against intubation-induced bronchoconstriction in asthma. Anesthesiology 2000;93:1198-204.

45. Guntupalli KK, Bandi V. Considerations in the mechanically ventilated severe asthmatic. Current Topics in Intensive Care No. 3. Dellinger RP (ed.), 1600 John F. Kennedy Blvd., Ste 1800 USA:Philadelphia, PA 19103-2899 W.B. Saunders Co, Ltd.; 1996. pp. 166-85.

46. Sarma VJ. Use of ketamine in acute severe asthma. Acta Anaesthesiol Scand 1992;36:106-7.

47. Lau TT, Zed PJ. Does ketamine have a role in managing severe exacerbation of asthma in adults? Pharmacotherapy 2001;21:1100-6.

48. Eames WO, Rooke GA, Wu RS, Bishop MJ. Comparison of the effects of etomidate, propofol and thiopental on respiratory resistance after tracheal intubation. Anesthesiology 1996;84:130711.

49. Corbridge TC, Hall JB. The assessment and management of adults with status asthmaticus. Am J Respir Crit Care Med 1995;151:1296-316.
50. Griffin D, Fairman N, Coursin D, Rawsthorne L, Grossman JE. Acute myopathy during treatment of status asthmaticus with corticosteroids and steroidal muscle relaxants. Chest 1992;102:510-4.

51. Leatherman JW, Fluegel WL, David WS, Davies SF, Iber C. Muscle weakness in mechanically ventilated patients with severe asthma. Am J Respir Crit Care Med 1996;153:1686-90.

52. Peigang Y, Marini JJ. Ventilation of patients with asthma and chronic obstructive pulmonary disease. Cur Opin Crit Care 2002;8:70-6.

53. Tuxen DV, Lan S. The effects of ventilatory pattern on hyperinflation, airway pressures, and circulation in mechanical ventilation of patients with severe air-flow obstruction. Am Rev Respir Dis 1987;136:872-9.

54. Leatherman JW, McArthur C, Shapiro RS. Effect of prolongation expiratory time on dynamic hyperinflation in mechanically ventilated patients with severe asthma. Crit Care Med 2004;32:15425.

55. Smith TC, Marini JJ. Impact of PEEP on lung mechanics and work of breathing in severe airflow obstruction. J Appl Physiol 1988;65:1488-99.

56. Darioli R, Perret C. Mechanical controlled hypoventilation in status asthmaticus. Am Rev Respir Dis 1984;129:385-7.

57. Rosengarten PL, Tuxen DV, Dziukas L, Scheinkestel C, Merrett K, Bowes G. Circulatory arrest induced by intermitted positive pressure ventilation in a patient with severe asthma. Anaesth Intensive Care 1991;19:118-21.

58. Williams TJ, Tuxen DV, Scheunkestel C, Czarny D, Bowes G. Risk factors for morbidity in mechanically ventilated patients with acute severe asthma. Am Rev Respir Dis 1992;146:607-15. 